\title{
EFFECTIVENESS SERVICE INFORMATION TO INCREASE CONCEPTION X'SELF STUDENT of SMA COUNTRY 1 ANGKOLA WEST
}

\author{
VITRIA LARSEMAN DELA \\ Universitas Muhammadiyah Tapanuli Selatan \\ Email: vitria.larseman@um-tapsel.ac.id
}

\begin{abstract}
Abstrak
This research is based of problems still lower him conception student x'self. Target of Research is to To know information service efektifitas in improving student $x$ 'self concept [pass/through] information service. Research method the used is research of True Experimental Design with PretestPosttest Control Group Design. With experiment class sampel that is XI IPS 1 counted 20 control and student that is class of XI IPS 2 counted 20 student so that the amount of sampel 40 student. Information service done/conducted by the three of times;rill, namely in first meeting execute pretest, second conducting information service bemberian and third conduct posttest. This data in analysis by using formula of wilcoxon ranks signed test and $\mathrm{Z}$ smirnov kolmogorov constructively SPSS version 20.00. Hasil finding [at] experiment group and group control there are make-up of which is deliverance signifikan result of pretest control and experiment posttest. Variable mean conception student x'self equal to 62.9000. ( Eksperimen postteste) while class control 60.3000. ( control posttest) this seen very difference of signifikan.Kesimpulan of this research Result of data processing, indicating that pelaksannaa of information service can improve class student $x$ 'self concept of XI IPS SMA Country 1 ANGKOLA WEST
\end{abstract}

Keyword: Service Information and Concept X'Self

\section{PENDAHULUAN}

Pendidikan mempunyai pengaruh yang dinamis dalam kehidupan manusia di masa depan. Pendidikan dapat mengembangkan berbagai potensi yang dimilikinya secara optimal, yaitu pengembangan potensi individu yang setinggi-tingginya dalam aspek fisik, intelektual, emosional, sosialdan spiritual, sesuai dengan tahap perkembangan serta karakteristik lingkungan fisik dan lingkungan sosial budaya di mana dia hidup. Pendidikan merupakan fenomena manusia yang sangat kompleks. Karena sifatnya yang kompleks itu, maka pendidikan dapat dilihat dan dijelaskan dari berbagai sudut pandang.

Menurut Burns (1993:51) konsep diri adalah hubungan antara sikap dan keyakinan tentang diri kita sendiri. Sedangkan Pemily (dalam Atwater, 1984), mendefesikan konsep diri sebagai sistem yang dinamis dan kompleks diri, keyakinan yang dimiliki seseorang tentang dirinya, termasuk sikap, perasaan, persepsi.
Menurut Hurlock (1990:58) Memberikan pengertian tentang konsep diri sebagai gambaran yang dimiliki orang tentang dirinya. Konsep diri ini merupakan gabungan dari keyakinan yang dimiliki individu tentang mereka sendiri yang meliputi karakteristik fisik, psikologis, sosial, emosional, aspirasi, dan prestasi.

Maslow (1962:279) berpendapat bahwa sebagaimana Freud melihat masa lalu masih ada didalam kehidupan sekarang ini pada masingmasing orang.

Konsepsi diri menjadi sebuah proses yang berkelanjutan, proses menilai yang bersifat organismik, bukan lagi bersifat statis tetapi mampu untuk menyesuaikan kembali dan berkembang sebagai pengalaman-pengalaman baru yang terintegrasikan. Lalu konsep diri menjadi berlandaskan di dalam pengalamanyang sejati, terbuka dan peka terhadap perasaanperasaan dari dalam dirinya, terhadap perasaanperasaan dari orang lain dan terhadap realitasrealitas lingkungannya. 
Berdasarkan latar belakang di atas, serta fenomena yang terjadi di sekolah maka penulis mengidentifikasikan masalah sebagai berikut :

1. Tentang keterlambatan maksudnya, para siswa belum dapat atau belum bisa $x$ mengatur waktunya seefesien mungkin dan tidak mematuhi peraturan yang ada di sekolah.

2. Banyaknya siswa yang belum mengenal siapa dirinya sendiri, apa hak serta kewajibannya baik dalam kehidupan pribadi maupun kehidupan sosial.

3. Banyaknya siswa yang kurang percaya diri dan belum mengetahui tentang bakat, minat, serta potensi yang dimilikinya.

\section{METODOLOGI}

Jenis penelitian yang digunakan peneliti dalam proposal ini adalah jenis penelitian eksperimen. Penelitian eksperimen adalah penelitian yang dimaksudkan untuk mengetahui ada tidaknya akibat dari 'sesuatu' yang di kenakan pada subjek selidik. Dengan kata lain penelitian eksperimen mencoba meneliti ada tidaknya hubungan sebab akibat. Caranya adalah dengan membandingkan satu atau lebih kelompok eksperimen yang diberi perlakuan dengan satu atau lebih kelompok pembanding yang tidak menerima perlakuan.

Menurut Mohammad N., (2005:84), "Desain penelitian adalah semua proses yang diperlukan dalam perencanaan dan pelaksanaan penelitian". Jenis penelitian ini adalah pre experiment (eksperiment tidak sebenarnya) atau quasi experiment (pura-pura). Peneliti menggunakan kelompok eksperimen karena ada perbandingan dengan kelompok kontrol, sehingga satu kelompok tes diberikan satu perlakuan yang sama sebelum dan sesudah mendapatkan perlakuan tertentu

\section{Populasi}

Sebelum mengadakan penelitian penelitian terlebih dahulu harus menentukan siapa yang akan menjadi subjek penelitian. Suharsini A., (2006:130) memberikan batasan mengenai populasi yaitu keseluruhan subjek penelitian.
Tabel. 1

\begin{tabular}{|c|c|c|c|c|}
\hline \multirow[b]{2}{*}{ No } & \multirow[b]{2}{*}{ Kelas } & \multicolumn{2}{|c|}{ Jumlah Siswa } & \multirow[b]{2}{*}{$\begin{array}{l}\text { Total } \\
\text { Siswa }\end{array}$} \\
\hline & & $\begin{array}{l}\text { Laki- } \\
\text { Laki }\end{array}$ & Perempuan & \\
\hline 1. & XI IA-1 & 14 orang & 26 orang & $\begin{array}{c}40 \\
\text { orang }\end{array}$ \\
\hline 2. & XI IA-2 & 16 orang & 26 orang & $\begin{array}{c}42 \\
\text { orang }\end{array}$ \\
\hline 3. & XI IS-1 & 15 orang & 25 orang & $\begin{array}{c}40 \\
\text { orang }\end{array}$ \\
\hline 4. & XI IS-2 & 17 orang & 24 orang & $\begin{array}{c}41 \\
\text { orang }\end{array}$ \\
\hline & Jumlah & 62 orang & 101 orang & $\begin{array}{c}163 \\
\text { orang }\end{array}$ \\
\hline
\end{tabular}

2. Sampel

Sampel adalah sebagian atau wakil populasi yang diteliti, Suharsini A., (2006:131) menyarankan jika jumlah subyeknya kurang dari 100, lebih baik diambil semua sehingga penelitiannya penelitian populasi. Karena jumlah populasi 163 orang maka pada penelitian ini jumlah siswa kelas XI IPS SMA Negeri 1 Angkola Barat yaitu 81 siswa, yang di ambil sampel pada penelitian ini adalah 40 siswa.

Tabel. 2

\begin{tabular}{|c|c|c|c|c|c|}
\hline \multirow[b]{2}{*}{ No } & \multirow[b]{2}{*}{ Kelas } & \multicolumn{2}{|c|}{ Jumlah Siswa } & \multirow{2}{*}{$\begin{array}{l}\text { Total } \\
\text { Siswa }\end{array}$} & \multirow[b]{2}{*}{ Keterangan } \\
\hline & & LK & PR & & \\
\hline 1. & $\begin{array}{c}\text { XI } \\
\text { IS-1 }\end{array}$ & $\begin{array}{c}6 \\
\text { orang }\end{array}$ & $\begin{array}{c}14 \\
\text { orang }\end{array}$ & $\begin{array}{c}20 \\
\text { orang }\end{array}$ & Eksperimen \\
\hline 2. & $\begin{array}{c}\text { XI } \\
\text { IS-2 }\end{array}$ & $\begin{array}{c}5 \\
\text { orang }\end{array}$ & $\begin{array}{c}15 \\
\text { orang }\end{array}$ & $\begin{array}{c}20 \\
\text { orang }\end{array}$ & Kontrol \\
\hline \multicolumn{2}{|c|}{ Jumlah } & $\begin{array}{c}11 \\
\text { orang }\end{array}$ & $\begin{array}{c}29 \\
\text { orang }\end{array}$ & $\begin{array}{c}40 \\
\text { orang }\end{array}$ & \\
\hline
\end{tabular}

\section{Teknik Pengumpulan Data}

Teknik penelitian yang dapat peneliti uraikan adalah sebagai berikut: persiapan penelitian yaitu mengadakan pendekatan dan konsultasi kepada guru pembimbing dan kepala sekolah di SMA Negeri1 Angkola Barat, tentang rencana 
penelitian yang akan dilakukan di sekolah, mempersiapkan surat izin penelitian yang akan diserahkan kepada kepala sekolah SMA Negeri1 Angkola Barat. Membuat jadwal penelitian yang meliputi pembuatan instrumen, analisis hasil skala untuk dijawab responden serta menganalisis uji instrumen sebagai alat ukur variabel.

Mempersiapkan instrumen alat pengumpul data termasuk membuat kisi-kisi pengembangan instrumen peserta analisis instrumen yang sesuai dengan aspek yang akan diungkap serta perhitungan skornya, menentukan variabel yang akan diteliti, menyusun dan mengadakan instrumen untuk selanjutnya disampaikan responden.

Jenis skala yang digunakan adalah jenis skala Likert. Skala ini dirancang dari kategori-kategori yang digunakan oleh Jersild (dalam buku Burns R.B.1993:130) di dalam mengklasifikasikan komposisi anak-anak mengenai diri mereka sendiri.

\section{Teknik Analisis Data}

Tehnik analisis statistik non parametrik yang digunakan untuk menguji dalam penelitian ini adalah uji jenjang bertanda Wilcoxon signed ranks test dan metode Kolmogorof-Smirnov bagi kelompok sampel ganda, pengujian hipotesis dengan cara uji jenjang bertanda dilakukan apabila peneliti ingin memastikan tentang ada atau tidaknya perbedaan kondisi setelah perlakuan tertentu diberikan.

Kemudian metode

Kolmogorov-

Smirnov bagi kelompok sampel ganda dititik beratkan pada upaya menguji validitas hipotesis nihil yang mengatakan kelompok sampel pertama dan kedua berasal dari populasi yang identik.

Oleh karena itu maka metode analisis data yang dilakukan dalam penelitian ini dijabarkan sebagai berikut:

1. Untuk mendeskripsikan perbedaan meningkatkan konsep diri siswa sebelum dan sesudah diberikan perlakuan baik kelas eksperimen maupun kelas kontrol, peneliti menggunakan analisis data dengan teknik Wilcoxon signed rank test dengan bantuan program SPSS versi 20.00. Analisis ini untuk menguji hipotesis nomor 1 dan nomor 2 .

2. Untuk menguji hipotesis meningkatkan konsep diri siswa setelah diberikan perlakuan pada kelas eksperimen dengan siswa kelas kontrol digunakan teknik Kolmogorov Smirnov 2-Independent Samples dengan bantuan program SPSS versi 20.00. Analisis ini untuk menguji hipotesis 3

\section{HASIL}

Secara spesifik penelitian ini adalah untuk mengetahui peningkatan konsep diri siswa dengan melalui layanan informasi. Data-data yang diperoleh adalah hasil pretest dan posttest berkait dengan meningkatkan konsep diri siswa. Instrumen untuk mengukur peningkatan konsep diri siswa yang digunakan adalah angket.

Berdasarkan data yang diperoleh, maka dapat dideskripsikan hasil penelitian sebelum dilakukan (pretest) dan setelah dilakukan perlakuan (posttest) dimana pengolahan data kuantitatif dilakukan menggunakan rumus SPSS versi 20.0 for windows.

\section{Perbandingan Hasil Angket Meningkatkan Konsep Diri SMA Negeri 1 Angkola Barat}

Tabel. 3

\begin{tabular}{|c|c|c|c|c|}
\hline \multirow[t]{2}{*}{ INDIKATOR } & \multicolumn{2}{|c|}{ Kelas Eksperimen } & \multicolumn{2}{|c|}{ Kelas Kontrol } \\
\hline & pretest & posttest & Pretest & $\begin{array}{c}\text { Posttes } \\
t\end{array}$ \\
\hline Harapan orang tua & 107 & 113 & 82 & 108 \\
\hline 2. Keadaan fisik & 133 & 156 & 88 & 96 \\
\hline 3. Sikap anggota keluarga & 53 & 55 & 29 & 34 \\
\hline Kematanagan biologis & 293 & 321 & 264 & 357 \\
\hline Pengaruh media massa & 44 & 48 & 37 & 41 \\
\hline $\begin{array}{ll}\text { 6. } & \text { Kesempatan untuk } \\
\text { menempuh pendidikan }\end{array}$ & 40 & 43 & 24 & 37 \\
\hline 7. Tuntutan sekolah & 96 & 102 & 73 & 85 \\
\hline $\begin{array}{l}\text { 8. Agama dan } \\
\text { kepercayaan }\end{array}$ & 40 & 42 & 25 & 34 \\
\hline $\begin{array}{l}\text { 9. Pengaruh dan pendapat } \\
\text { teman sebaya }\end{array}$ & 127 & 130 & 104 & 126 \\
\hline $\begin{array}{l}\text { 10. Keadaan ekonomi } \\
\text { keluarga }\end{array}$ & 41 & 51 & 35 & 36 \\
\hline 11. Problem keluarga & 112 & 117 & 102 & 102 \\
\hline 12. Sikap teman sebaya & 115 & 129 & 97 & 110 \\
\hline JUMLAH & 1201 & 1307 & 960 & 1166 \\
\hline
\end{tabular}

Data di atas diambil dari hasil tabulasi per indikator dari pretest-posttest kontrol dan 
prestest-posttest eksperimen dan dengan adanya dalam kehidupannya serta mampu secara pribadi tabel perbandingan di atas dapat dilihat terjadinya berpikir lebih terarah khususnya untuk peningkatan sebelum dan sesudah diberikannya meningkatkan konsep diri. Berdasarkan hal perlakuan. tersebut maka peningkatan konsep diri dapat

Dari tabel di atas jika di lihat dari hasil ditingkatkan dengan menggunakan layanan perbandingan interval yaitu sebagai berikut : informasi, hal ini di karena siswa dapat membangun hal-hal baru yang lebih efektif dan

Interval perbandingan hasil angket berpikir yang positif serta mengembangkan untuk meningkatkan konsep diri kelas potensi yang ada pada dirinya kearah yang lebih eksperimen dan kelas kontrol

Tabel. 4

\begin{tabular}{|c|c|c|c|c|c|c|c|}
\hline \multirow[t]{2}{*}{ No } & \multirow{2}{*}{$\begin{array}{l}\text { Nilai } \\
\text { Interva } \\
1\end{array}$} & \multicolumn{2}{|c|}{ Eksperimen } & \multicolumn{2}{|c|}{ Kontrol } & \multirow{2}{*}{\multicolumn{2}{|c|}{$\begin{array}{l}\text { Kategori } \\
\text { KESIMPULAN }\end{array}$}} \\
\hline & & pretest & Posttest & pretest & posttest & & \\
\hline 1. & $90-100$ & & 87,1 & & & $\begin{array}{l}\text { Sangat } \\
\text { Baik }\end{array}$ & nenelitian \\
\hline 2. & $70-80$ & 80 & & & 77,7 & & \\
\hline 3. & $50-60$ & & & 64 & & Cukup ${ }^{\text {ta }}$ & if untuk menıngkatkan \\
\hline 4. & $20-40$ & & & & & Kurangkon & sep diri siswa agar siswa mengetahui dan \\
\hline 5. & 0 & & & & & Gagal mer & dirinya \\
\hline
\end{tabular}

Dilihat dari tabel di atas nilai selajutnya dimanfaatkan untuk diaplikasikan perbandingan antara pretest-posttest kontrol dalam hidupnya sehari-hari. Pemberian informasi dan prestest-posttest eksperiemen. Yang ini juga diperlukan untuk membekali individu terjadi adalah nilai dari pretest-posttest dengan berbagai pengetahuan tentang eksperimen lebih tinggi dibandingkan kepribadian diri karena setiap individu itu unik, prestest-posttest kontrol.

keunikan itu akan membawakan pola-pola pengambilan keputusan dan bertindak yang

\section{PEMBAHASAN}

Siswa dalam kegiatan layanan ini banyak memperoleh pengetahuan yang berguna bagi kehidupan sehari-harinya, sesuai dengan pendapat Tohirin (2011:147), yaitu layanan informasi bertujuan agar individu (siswa) mengetahui menguasai informasi yang selanjutnya dimanfaatkan untuk keperluan hidupnya sehari-hari dan perkembangan dirinya. Penguasaan akan informasi dapat digunakan untuk mencegah timbulnya masalah, pencegahan suatu masalah, untuk memelihara dan mengembangkan potensi individu serta mmungkinkanindividu yang bersangkutan membuka diri dalam mengaktualisasikan hakhaknya.

Berdasarkan kutipan di atas disimpulkan bahwa layanan informasi merupakan cara untuk meningkatkan pengetahuan diri, yang kemudian informasi, dimana rata-rata konsep diri siswa informasi tersebut akan dipergunakan untuk kelas eksperimen lebih tinggi dibandingkan ratamenyusun rencana dan membuat keputusan rata kelas kontrol setelah diberikan perlakuan berbeda-beda disesuaikan dengan aspek-aspek kepribadian masing-masing individu.

Layanan ini merupakan kegiatan yang dilakukan oleh petugas bimbingan untuk membekali siswa tentang pengetahuan serta pemahaman tentang konsep diri agar mereka dapat mengetahui, memahami dirinya sendiri dan mereka dapat merencanakan kehidupannya kedepankearah yang lebih baik dan positif.

Secara khusus penelitian ini dapat disimpulkan (1) terdapat peningkatan konsep diri kelas eksperimen sebelum (pretest) dan sesudah (posttest) mengikuti kegiatan layanan informasi, dimana rata-rata kemampuan mengenali diri sendiri meningkat; (2) terdapat peningkatan konsep diri siswa kelas kontrol sebelum (pretest) dan sesudah (posttest) mengikuti layanan informasi; dan (3) ada peningkatan konsep diri siswa kelas eksperimen yang diberikan layanan rata kelas kontrol setelah diberikan perlakuan 
Volume 3 Nomor 2, Halaman 1-77, Juli-Desember 2018

RISTEKDIK / Jurnal Bimbingan dan Konseling

P-ISSN: 2527-4244, E-ISSN : 2541-206X

\section{DAFTAR PUSTAKA}

Burns, R.B. 1993. Konsep Diri :Teori, Pengukuran, Perkembangan dan Perilaku, Jakarta: Arca.

Hurlock, E.B. 1990. Psikologi Perkembangan. Jakarta :Penerbit Erlangga.

Mohammad N., 2005.Metode penelitian. Jakarta: Ghalia Indonesia.

Suharsini A., 2006. Prosedur Penelitian Suatu Pendekatan Praktek. Jakarta. Rineka Cipta.

Tohirin. 2011. Bimbingan dan konseling disekolah dan madrasah (berbasis integrasi). Bandung : Rajagrafindo Persada.

Maslow. 1962. Konsep Diri :Teori, Pengukuran, Perkembangan dan Perilaku, Jakarta: Arca 